\title{
PENGARUH PELATIHAN DAN MOTIVASI TERHADAP KINERJA PEGAWAI PADA PUSKESMAS HUTARAJA KECAMATAN MUARA BATANG TORU
}

\author{
Nofinawati, Ahmad Iqbal Tanjung, Irdayani Siregar \\ IAIN PADANGSIDIMPUAN
}

\author{
Jalan T. Rizal Nurdin Km. 4.5 Sihitang, Padangsidimpuan \\ e-mail:

\section{Abstrak}

Penelitian ini dilatarbelakangi oleh masalah pemberian motivasi dan pelatihan, tetapi belum menciptakan perubahan dan peningkatan dalam kinerja pegawai. Hal ini dilihat dari hasil kerja yang belum maksimal, sepertitidak disiplin atau tidak hadirnya pegawai semakin meningkat, pelayanan puskesmas kurang baik, kurang memperhatikan pasien, karena kurang komunikasi antara pegawai dengan pasien.Rumusan masalah adalahapakah pelatihan dan motivasi berpengaruh secara parsial dan simultan terhadap kinerja Pegawai pada Puskesmas Hutaraja Kecamatan Muara Batang Toru. Tujuan penelitian yaitu untuk mengetahui pelatihan dan motivasi berpengaruh secara parsial dan simultan terhadap kinerja Pegawai pada Puskesmas Hutaraja Kecamatan Muara Batang Toru. Pembahasan penelitian ini berkaitan dengan bidang ilmu manajemen sumber daya manusia. Sehubungan dengan itu pendekatan yang dilakukan adalah teori-teori yang berkaitan dengan pelatihan, motivasi dan kinerja.Penelitian ini merupakan penelitian kuantitatif. Sampel yang digunakan dalam penelitian ini sebanyak 51 orang, sehingga penelitiannya merupakan penelitian populasi. Teknik pengumpulan data yang digunakan adalah teknik angket (kuisioner) dan wawancara. Teknik analisispenelitian ini menggunakan uji validitas, uji reliabilitas, uji normalitas, uji linearitas, uji asumsi klasik, uji regresi linear berganda dan uji hipotesis dengan bantuan softwareSPSS versi 23.Hasilpenelitian yaitu nilai R sebesar o,606 dannilai R Square = 0,367artinya pelatihan dan motivasi mampu menjelaskan variabel dependen atau kinerja pegawai sebesar 36,7 persen sedangkan 63,3 persen dijelaskan oleh variabel laindiluar penelitian. Pelatihan berpengaruh secara parsial terhadap kinerja pegawai, dengan nilai thitung $>\operatorname{tabel}(4,881>1,676)$. Variabel motivasi berpengaruh secara parsial terhadap kinerja pegawai, dengan thitung $>t_{\text {tabel }}(1,701>1,676)$. Variabel pelatihan dan motivasiberpengaruhsecara simultan terhadap kinerja Pegawai dengan nilai Fhitung $>F_{\text {tabel }}(13,941>3,19)$.

Kata Kunci : Pelatihan, Motivasi dan Kinerja 


\section{PENDAHULUAN}

Setiap organisasi, baik besar maupun kecil membutuhkan sumber daya manusia yang berkualitas. Hal tersebut dikarenakan sumber daya manusia merupakan salah satu faktor kunci dari keberhasilan suatu organisasi. Maka dari itu manajemen yang baik dan dapat menyesuaikan diri dengan lingkungan pekerjaan dibutuhkan untuk mengatasi hambatan-hambatan sumber daya manusia yang ada. Zaman sekarang persaingan yang terjadi diantara organisasi semakin ketat, sehingga menuntut organisasi untuk berkembang dan dapat beradaptasi. Salah satu cara yang dapat dilakukan adalah dengan memberi pelatihan dan meningkatkan motivasi tenaga kerja. Hal tersebut bertujuan untuk memperbaiki kinerja suatu organisasi, sehingga dapat mengatasi masalahmasalah dan dapat bersaing secara kompetitif. Mengatur pegawai merupakan hal yang cukup kompleks. Hal tersebut dikarenakan pegawai memiliki pikiran, perasaan, keinginan dan latar belakang yang berbeda-beda yang dibawa kedalam suatu perusahaan. Peran penting dalam proses manajemen kinerja termasuk pelatihan dan motivasi.

Pelatihan adalah proses terintegrasi yang digunakan oleh perusahaan untuk memastikan agar para pegawai bekerja untuk mencapai tujuan organisasi. Ini berarti melakukan pendekatan terintegrasi dan berorientasi pada tujuan untuk menugaskan, melatih, menilai dan memberi penghargaan pada kinerja pegawai. ${ }^{1}$ Pelatihan bukan hanya biaya, pelatihan juga merupakan investasi suatu organisasi untuk mencapai tujuan organisasi.Pelatihan tidak bermanfaat jika pekerja tidak mendapatkan kemampuan atau motivasi dari pelatihan yang diikuti dan tidak mengabaikan dampak positif serta keuntungan positif terhadap keuntungan organisasi.

Motivasi adalah proses memengaruhi atau mendorong dari luar terhadap seseorang atau kelompok kerja agar mereka mau melaksanakan sesuatu yang telah ditetapkan dan motivasi kerja adalah suatu yang menimbulkan dorongan atau semangat kerja. ${ }^{2}$ Perusahaan yang baik harus dapat membuat pegawai termotivasi dalam bekerja. Salah satunya adalah dengan cara memenuhi kebutuhan-kebutuhan pegawai seperti memberikan kesempatan untuk praktikpraktik aktif, jam istirahat yang cukup dan fasilitas kerja yang terpenuhi. Sebaliknya apabila kebutuhan pegawai tidak terpenuhi, dapat menurunkan motivasi pegawai dalam perusahaan dan dapat menurunkan kinerja pegawai.

Pusat kesehatan masyarakat (Puskemas) Hutaraja merupakan salah satu organisasi kesehatan fungsional yang merupakan pusat pengembangan kesehatan masyarakat dan membina peran serta masyarakat disamping memberikan pelayanan secara menyeluruh dan terpadu kepada masyarakat khususnya kecamatan Muara Batang Toru dengan luas wilayah ke tujuh setapanuli selatan menurut kecamatan $307.00 \mathrm{~km}^{2}$ dengan jumlah penduduk

\section{0}

${ }^{1}$ Dessler Gery, Managemen Sumber Daya Manusia (Indonesia: PT Intan Sejati Klaten 2006), hlm. $281-282$

${ }^{2}$ Sadili Samsuddin, Manajemen Sumber Daya Manusia (Bandung: CV. Pustaka Setia, 2005), hlm. 
15.430 jiwa dalam bentuk kegitan pokok. Dalam melaksanakan tugasnya sebagai pelayanan publik Puskesmas Hutaraja memiliki pegawai sebanyak 51 orang.

Pusat kesehatan masyarakat Hutaraja telah melakukan berbagai macam pelatihan dalam bidang masing-masing staf. 3 Dengan pelatihan-pelatihan yang diikuti diharapkan dapat meningkatkan kinerja pegawai, akan tetapi dilihat dari rekapitulasi kehadiran pegawai UPT Puskesmas tahun 2017 masih banyak pegawai yang tidak hadir dan malas bekerja.

Tabel I.1

DAFTAR REKAPITULASI KEHADIRAN PEGAWAI UPT PUSKESMAS BATANG TORU TAHUN 2017

\begin{tabular}{|l|c|c|c|c|c|c|}
\hline \multirow{2}{*}{ BULAN } & \multicolumn{5}{|c|}{ PENGURANGAN TAMBAHAN PENGHASILAN } \\
\cline { 2 - 7 } & $\begin{array}{c}\mathrm{A} \\
\text { (Kali) }\end{array}$ & $\begin{array}{c}\mathrm{I} \\
(\text { Kali })\end{array}$ & $\begin{array}{c}\text { S } \\
\text { (Kali) }\end{array}$ & $\begin{array}{c}\text { DL } \\
(\text { Kali })\end{array}$ & $\begin{array}{c}\text { TB } \\
(\text { Kali })\end{array}$ & $\begin{array}{c}\text { C } \\
(\text { Kali })\end{array}$ \\
\hline MARET & 29 & 34 & - & 17 & 26 & 23 \\
\hline APRIL & - & 5 & - & 111 & 23 & 34 \\
\hline MEI & - & 1 & 2 & 156 & 24 & 24 \\
\hline JUNI & 36 & - & - & 107 & 18 & - \\
\hline JULI & 52 & - & 2 & 184 & 26 & - \\
\hline AGUSTUS & 52 & - & 2 & 214 & 26 & - \\
\hline SEPTEMBER & 24 & 3 & - & 215 & 24 & - \\
\hline OKTOBER & 52 & - & - & 211 & 26 & 16 \\
\hline NOVEMBER & 78 & - & - & 260 & 26 & 26 \\
\hline DESEMBER & 69 & - & - & 208 & 23 & 23 \\
\hline JUMLAH & 392 & 43 & 6 & 1683 & 242 & 146 \\
\hline
\end{tabular}

Data diolah dari Laporan Rekapitulasi Kehadiran Pegawai Tahun 2017

Berdasarkan tabel diatas menunjukkan tiap bulan ketidakhadiran pegawai UPT Puskesmas semakin meningkat. Pada tahun 2017 ketidakhadiran tanpa keterangan Alfa (A) sebanyak 390 kali, Izin (I) sebanyak 43 kali, Sakit (S) sebanyak 6 kali, Dinas Lapangan (DL) sebanyak 1683 kali, Tugas Belajar (TB) sebanyak 242 kali, Cuti (C) sebanyak 146 kali. Hal ini menunjukkan bahwa ketidak hadiran pegawai UPT Puskesmas Batang Toru setiap bulannya meningkat meskipun telah dilakukan pelatihan namun ketidakhadiran tanpa izin tetap saja meningkat, ini menunjukkan bahwa semangat kinerja pegawai UPTD Puskesmas masih rendah.

Setelah melakukan kegiatan pelatihan, pegawai diharapkan termotivasi untuk bekerja lebih baik, lebih efektif dan dapat mencapai hasil yang maksimal. Karena motivasi merupakan hal yang paling penting dalam melaksanakan suatu pekerjaan. Berdasarkan uraian dan permasalahan diatas maka peneliti tertarik untuk mengetahui apakah variabel independen pelatihan dan motivasi yang diberikan berpengaruh terhadap kinerja pegawai.

${ }^{3}$ Hasil wawancara, Bapak Firman Simatupang (Ka.UPTD Puskesmas, pada Puskesmas Hutaraja Kecamatan Muara Batang Toru), Rabu, 11 Oktober 2017, Jam 10.00 WIB 


\section{LANDASAN TEORI}

\section{Pelatihan}

Pelatihan adalah suatu usaha untuk meningkatkan pengetahuan dan kemampuan pegawai dalam melaksanakan pekerjaannya lebih efektif dan efisien. Program pelatihan adalah serangkaian program yang dirancang untuk meningkatkan pengetahuan dan kemampuan pegawai dalam hubungannya dalam pekerjaannya. Efektivitas program pelatihan adalah suatu istilah untuk memastikan apakah program pelatihan dijalankan dengan efektif dalam mencapai sasaran yang ditentukan. 4 Pelatihan merupakan bagian dari pendidikan, pelatihan bersifat sfesifik, praktis dan segera. Sfesifik artinya pelatihan berhubungan dengan bidang pekerjaan yang dilakukan.Praktis dan segera berarti yang sudah dilatihkan dapat dipraktikkan.Umumnya pelatihan dimaksudkan untuk memperbaiki penguasaan berbagai keterampilan kerja dalam waktu yang relative singkat.

Metode pelatihan dapat dibagi menjadi dua kategori, yakni:

a) In-house atau on-site training, berupa on the job training,seminar atau lokakarya, instruksi lewat media (video, tape dan satelit) dan instruksi yang berbasis komputer.

b) External atau outside training, terdiri dari kursus, seminar dan lokakarya yang diselenggarakan oleh asosiasi professional dan lembaga pendidikan.

Ada tiga pendekatan pokok dalam pelatihan, yakni:

a) Pendekatan internal, pendekatan yang digunakan untuk memberikan pelatihan dengan fasilitas dari organisasi. Pendekatan ini meliputi one on one training, on the job computer based training, formal group instructiondan media based in instruction.

b) Pendekatan eksternal, pendekatan yang dilaksanakan dengan cara mendaftarkan pegawai pada program atau kegiatan yang diberikan oleh lembaga pemerintah, organisasi profesional dan perusahan pelatihan swasta.

c) Pendekatan kemitraan, terjalin kemitraan antara perusahaan bisnis dengan perguruan tinggi untuk memberikan customized training. Kemitraan dengan perguruan tinggi memberikan keuntungan kepada perusahaan yang ingin menyelenggarakan pelatihan bagi para pegawai.5

Tujuan diadakan pelatihan yang diselenggarakan oleh organisasi terhadap pegawai dikarenakan organisasi menginginkan adanya perubahan dalam kinerja pegawai sehingga mencapai tujuan organisasi yaitu meningkatkan penghayatan jiwa dan ideology, meningkatkan kualitas kerja, meningkatkan ketepatan perencanaan sumber daya manusia, meningkatkan sikap moral dan semangat kerja serta meningkatkan kesehatan dan keselamatan jiwa.

${ }^{4}$ Herman Sofyandi, Manajemen Sumber Daya Manusia (Yogyakarta: Graha Ilmu, 2008), hlm.113

${ }^{5}$ Ibid., hlm. 112 


\section{Motivasi}

Motivasi dalam prosesnya dapat terjadi dari dua bagian yakni motivasi intrinsik dan motivasi ekstrinsik. ${ }^{6}$ Motivasi intrinsik adalah dorongan yang merupakan keinginan murni dari individu untuk melakukan sesuatu. Sedangkan motivasi ekstrinsik adalah dorongan dari luar atau ransangan dari lingkungan yang mengakibatkan seorang individu ingin berbuat untuk itu. 7

Teori motivasi Menurut Maslow, setiap individu memiliki kebutuhan yang tersusun secara hierarki dari tingkat yang paling rendah telah terpenuhi maka timbullah kebutuhan lain yang lebih tinggi. ${ }^{8}$ Hierarki kebutuhan menurut Abraham Maslow, sebagai berikut

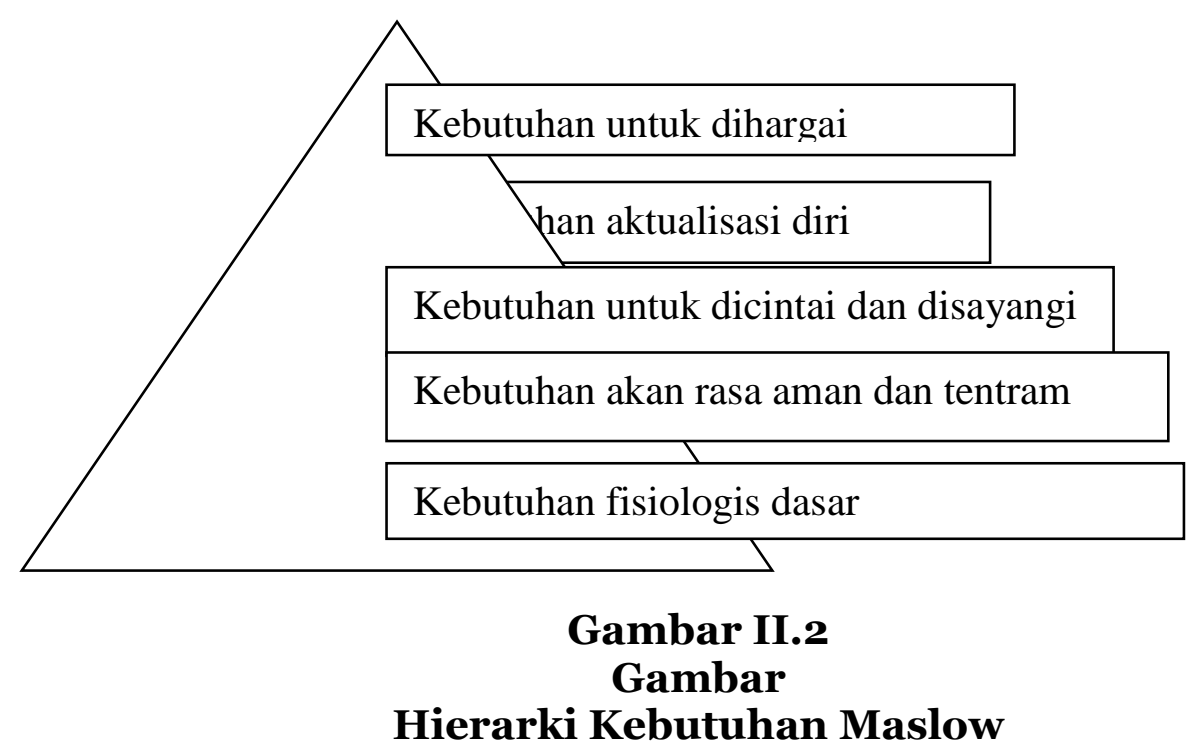

Tujuan dari pemberian motivasi ini adalah Mendorong gairah dan semangat kerja pegawai, meningkatkan moral dan kepuasan bekerja pegawai, meningkatkan Produktivitas kerja pegawai, menciptakan suasana dan hubungan yang baik, mengefektifkan pengadaan pegawai, meningkatkan kesejahteraan pegawai,m empertinggi rasa tanggung jawab pegawai terhadap tugas-tugasnya.

Pemberian motivasi ini memiliki beberapa metode yaitu: 1) metode langsung metode material dan non material diberikan langsung kepada pegawai untuk memenuhi kebutuhan dan keputusan pegawai. Misalnya seperti memberi pujian, penghargaan, bonus dan piagam. 2) Metode tidak langsung yaitu metode yang diberikan berupa fasilitas yang mendukung serta menunjang gairah kerja, sehingga para pegawai betah dan bersemangat dalam melakukan pekerjaan.

${ }^{6}$ Ibid.,hlm. 63

${ }^{7}$ Muda, Iskandar dan Abdul Nasser Hasibuan, Public Discovery of The Concept of Money with Value of Time Emerald Reach Proceeding Series (Proceeding of MICoMS 2017), Vol 1 pp.255-261

\footnotetext{
${ }^{8}$ Anwar Prabu Mangkunegara, Op.Cit., hlm.283-284
} 
Misalnya, kursi yang empuk, ruangan kerja yang tenang dan nyaman, suasana dan lingkungan kerja yang baik dan penempatan pegawai yang tepat. 9

\section{Kinerja}

Kinerja merupakan hasil kerja yang dapat dicapai oleh seseorang atau sekelompok orang dalam suatu organisasi, sesuai dengan wewenang dan tanggung jawab masing-masing, dalam rangka upaya mencapai tujuan organisasi. ${ }^{10}$ Kinerja adalah bagaimana seseorang diharapkan dapat berfungsi dan berperilaku sesuai dengan tugas yang dibebankan kepadanya. Setiap harapan mengenai bagaimana seseorang harus berperilaku dalam melaksanakan tugas, berarti menunjukkan suatu peran dalam organisasi.Kinerja merupakan hasil kerja yang dapat dicapai oleh seseorang atau sekelompok orang dalam suatu organisasi, sesuai dengan wewenang dan tanggung jawab masing-masing, dalam rangka upaya mencapai tujuan organisasi. ${ }^{11}$ Kinerja adalah bagaimana seseorang diharapkan dapat berfungsi dan berperilaku sesuai dengan tugas yang dibebankan kepadanya. Setiap harapan mengenai bagaimana seseorang harus berperilaku dalam melaksanakan tugas, berarti menunjukkan suatu peran dalam organisasi.Cormick dan Tiffin dalam buku Edy Sutrisno mengemukakan bahwa kinerja adalah kuantitas, kualitas dan waktu yang digunakan dalam menjalankan tugas. ${ }^{12}$

Faktor-faktor yang memengaruhi kinerja menurut Steers adalah: ${ }^{13}$ 1) Kemampuan, kepribadian dan minat kerja. 2) Kejelasan dan penerimaan atau penjelasan peran seorang pekerja yang merupakan taraf pengertian dan penerimaan seseorang atas tugas yang diberikan kepadanya. 3) Tingkatmotivasi pekerja yaitu daya energi yang mendorong, mengarahkan dan mempertahankan perilaku. Dalam mengukur kinerja pegawai dapat dilakukan menurut Bernandi dan Russell yaitu berikut:14 1) Quantity of work, jumlah kerja yang dilakukan dalam suatu priode yang ditentukan. 2) Quality of work, kualitas kerja yang dicapai berdasarkan syarat-syarat kesesuaian dan kesiapannya. 3) Job knowledge, luasnya pengetahuan mengenai pekerjaan dan keterampilannya. 4) Creativenes, keaslian gagasan-gagasan yang dimunculkan dari tindakantindakan untuk menyelesaikan persoalan-persoalan yang timbul. 5)

\footnotetext{
${ }^{9}$ Hasibuan, Abdul Nasser, Effects of Auditor Quality on Market-besed and Accountingbased Financial Statement Quality and Its Impacts on Economic Consequences (A Case Indonesian Capital Market), Internasional Journal of Economic Research No.14 (2017). 2009), hlm. 170

${ }^{10}$ Edy Sutrisno, Manajemen Sumber Daya Manusia (Jakarta: Kencana Prenada Media Group, 2009), hlm. 170

${ }^{11}$ Edy Sutrisno, Manajemen Sumber Daya Manusia (Jakarta: Kencana Prenada Media Group,

${ }^{12}$ Ibid., hlm. 172

${ }^{13}$ Arsi Laksmi Riani, BudayaOrganisasi (Yogyakarta: Graha Ilmu, 2011), hlm. 100-101

${ }^{14}$ Ibid., hlm. 99-100
} 
Cooperation, kesediaan untuk bekerjasama dengan orang lain atau sesama anggota organisasi. 6) Dependability, kesadaran untuk dapat dipercaya dalam hal kehadiran dan penyelesaian kerja. 7) Initiative, semangat untuk melaksanakan tugas-tugas baru dan memperbesar tanggung jawabnya. 8) Personal qualities, menyangkut kepribadian, kepemimpinan, keramah tamahan dan integritas pribadi.

\section{METODE PENELITIAN}

Jenis penelitian yang digunakan dalam penelitian ini adalah penelitian kuantitatif. Penelitian ini menggunakan seluruh pegawai yang telah mendapatkan motivasi serta pelatihan atau penelitian populasi yaitu seluruh pegawai Puskesmas Hutaraja Kecamatan Muara Batang Toru yang berjumlah 51pegawai. Dan teknik pengumpulan datanya yaitu: angket, wawancara dan observasi. Dalam melakukan analisis data menggunakan uji validitas, uji reliabilitas, uji normalitas, uji linearitas, uji asumsi klasik, analisis regresi berganda. Uji koefisien determinasi, uji hipotesis.

\section{HASIL PENELITIAN}

\section{Uji Validitas}

Uji validitas berguna untuk mengukur valid tidaknya suatu kuisioner. Suatu kuisioner dikatakan valid jika pernyataan pada kuisioner tersebut mampu mengungkapkan sesuatu yang akan diukur oleh kuisioner.

1) Uji Validitas Pelatihan $\left(X_{2}\right)$

Tabel IV.1

Uji Validitas Pelatihan ( $\left.\mathbf{X}_{1}\right)$

\begin{tabular}{|c|c|c|c|}
\hline Pernyataan & rhitung & rtabel & Keterangan \\
\hline S_1 & 0,598 & \multirow{10}{*}{$\begin{array}{c}\text { Instrumen valid } \\
\text { jika rhitungpositif } \\
\geq \text { rtabel. Nilai } \\
\text { rtabeluntuk df = } \\
\text { n-2 }(51-2)=49 \\
\text { dengan taraf } \\
\text { signifikan 5\%, } \\
\text { sehingga } \\
\text { diperoleh } \\
\text { rtabelSebesar } \\
\text { o,275 }\end{array}$} & Valid \\
\hline S_2 & 0,196 & & Tidak Valid \\
\hline S_3 & 0,426 & & Valid \\
\hline S_4 & 0,390 & & Valid \\
\hline S_5 & 0,390 & & Valid \\
\hline S_6 & 0,499 & & Valid \\
\hline S_7 & 0,598 & & Valid \\
\hline S_8 & 0,769 & & Valid \\
\hline S_9 & 0,769 & & Valid \\
\hline S_10 & 0,769 & & Valid \\
\hline
\end{tabular}

Sumber: Data primer yang diolah pada SPSS versi 23, 2018

Uji validitas variabel pelatihan pada tabel IV.1 dapat disimpulkan bahwa angket mengenai pelatihandari soal 1,3 samapai dengan 10 adalah valid,karena item tersebut memiliki nilai $r_{h i t u n g}>r_{\text {tabel }}$ dengan $n=51$ maka 
diperoleh rtabeladalaho,275. Soal nomor 2 adalah tidak valid sebab item tersebut memiliki nilai $r_{\text {hitung }}<$ rtabel.Sehingga angket variabel pelatihan dinyatakan 9 soal valid dan 1 soal tidak valid.

2) Uji Validitas Motivasi $\left(\mathrm{X}_{2}\right)$

Tabel IV.2

Uji Validitas Motivasi $\left(\mathbf{X}_{2}\right)$

\begin{tabular}{|c|c|c|c|}
\hline Pernyataan & rhitung & rtabel & Keterangan \\
\hline $\mathrm{S} \_1$ & 0,540 & \multirow{10}{*}{$\begin{array}{c}\text { Instrumen valid } \\
\text { jika rhitungpositif } \\
\geq \text { rtabel. Nilai } \\
\text { rtabeluntuk df = } \\
\text { n-2 }(51-2)=49 \\
\text { dengan taraf } \\
\text { signifikan 5\%, } \\
\text { sehingga } \\
\text { diperoleh } \\
\text { rtabelSebesar } \\
\text { 0,275 }\end{array}$} & Valid \\
\hline S_2 & 0,394 & & Valid \\
\hline S_3 & 0,645 & & Valid \\
\hline S_4 & 0,460 & & Valid \\
\hline S_5 & 0,694 & & Valid \\
\hline S_6 & 0,425 & & Valid \\
\hline S_7 & 0,623 & & Valid \\
\hline S_8 & 0,614 & & Valid \\
\hline S_9 & 0,559 & & Valid \\
\hline S_10 & 0,324 & & Valid \\
\hline
\end{tabular}

Sumber: Data primer yang diolah pada SPSS versi 23, 2018

Uji validitas variabel motivasi pada tabel IV.2 dapat disimpulkan bahwa semua soal angket variabel motivasi adalah valid,Sebab item tersebut memiliki nilai rhitung $>\mathrm{r}_{\text {tabel. }}$

3) Uji Validitas Kinerja Pegawai (Y)

\section{Tabel IV.3}

Uji Validitas Kinerja Pegawai (Y)

\begin{tabular}{|c|c|c|c|}
\hline Pernyataan & Phitung & \multirow{11}{*}{$\begin{array}{c}\text { rtabel } \\
\text { Instrumen valid } \\
\text { jika rhitungpositif } \\
\geq \text { rtabel. Nilai } \\
\text { rtabeluntuk df }= \\
\text { n-2 }(51-2)=49 \\
\text { dengan taraf } \\
\text { signifikan } 5 \%, \\
\text { sehingga } \\
\text { diperoleh } \\
\text { rtabelsebesar } \\
\text { 0,275 }\end{array}$} & Keterangan \\
\hline S_1 & 0,567 & & Valid \\
\hline S_2 & 0,281 & & Tidak Valid \\
\hline S_3 & 0,359 & & Valid \\
\hline S_4 & 0,440 & & Valid \\
\hline S_5 & 0,567 & & Valid \\
\hline S_6 & 0,207 & & Valid \\
\hline S_7 & 0,388 & & Valid \\
\hline S_8 & 0,401 & & Valid \\
\hline S_9 & 0,365 & & Valid \\
\hline S_10 & 0,269 & & Tidak Valid \\
\hline
\end{tabular}

Sumber: Data primer yang diolah pada SPSS versi 23, 2018

Uji validitas variabel motivasi pada tabel IV.3 dapat disimpulkan bahwa angket mengenai motivasi soal nomor 2 dan 10 adalah tidak 
valid,karena item tersebut memiliki nilai $r_{\text {hitung }}<$ rtabel dengan $\mathrm{n}=51$ maka diperoleh rtabeladalah 0,275 . Sedangkan angket soal nomor 1,3,4,5,6,7,8, dan 9 adalah valid. Sebab item tersebut memiliki nilai $r_{h i t u n g}>$ rtabel.Sehingga angket variabel motivasi dinyatakan 8 soal valid dan 2 soal tidak valid.

Berikut ini tabel rangkuman dari semua variabel yang diuji validitasnya:

Tabel IV.4

Hasil Pengujian Validitas Semua Variabel

\begin{tabular}{|l|c|c|c|}
\hline Variabel & $\begin{array}{c}\text { Jumlah } \\
\text { Butir Soal }\end{array}$ & $\begin{array}{c}\text { Jumlah } \\
\text { Soal } \\
\text { Valid }\end{array}$ & $\begin{array}{c}\text { Jumlah } \\
\text { Soal } \\
\text { Gugur }\end{array}$ \\
\hline Pelatihan & 10 & 9 & 1 \\
\hline Motivasi & 10 & 10 & 0 \\
\hline $\begin{array}{l}\text { Kinerja } \\
\text { Pegawai }\end{array}$ & 10 & 8 & 2 \\
\hline Total & $\mathbf{3 0}$ & $\mathbf{2 7}$ & $\mathbf{3}$ \\
\hline
\end{tabular}

Sumber: Data primer yang diolah, 2018

Berdasarkan tabel diatas, menunjukkan bahwa variabel pelatihan terdapat 10 soal, setelah dilakukan uji validitas ternyata 1 soal dinyatakan tidak valid. Artinya hanya 9 butir soal yang dapat digunakan untuk pengolahan data selanjutnya Pada variabel motivasi terdapat 10 soal, kemudian setelah dilakukan uji validitas maka hasil yang diperoleh dalah valid. Variabel kinerja pegawai terdapat 10 butir soal, setelah dilakukan uji validitas hasil menunjukkan 2 soal dinyatakan tidak valid. Artinya hanya 8 butir soal yang dapat digunakan untuk pengolahan data selanjutnya Dengan demikian, dari 30 butir soal terdapat 3 soal yang tidak valid/gugur, sedangkan untuk soal yang valid sebanyak 27 soal.

\section{Uji Reabilitas}

Realibilitas merupakan salah satu syarat penting bagi peneliti, reliabilitas sama dengan konsistensi. Suatu instrument penelitian dikatakan tinggi apabila tes yang dibuat mempunyai hasil konsisten. Uji reliabilitas bertujuan untuk melihat apakah instrument penelitian merupakan instrument yang handal dan dapat di percaya.

Hasil Uji Reliabilitas didasarkan pada nilai Cronbach's alpha (a), menunjukkan semua variabel yang diteliti memenuhi unsur reliabilitas dengan nilai Cronbach's alpha( $\alpha)>0,6$. Berikut hasil pengujian reliabilitas.

\section{Tabel IV.5}


Hasil Uji Reliabilitas

\begin{tabular}{|l|l|l|l|}
\hline Variabel & Cronbach's alpha & $\begin{array}{l}\text { Jumlah } \\
\text { Item }\end{array}$ & Keterangan \\
\hline Pelatihan & 0,780 & 9 & Reliabel \\
\hline Motivasi & 0,699 & 10 & Reliabel \\
\hline Kinerja Pegawai & 0,631 & 8 & Reliabel \\
\hline
\end{tabular}

Sumber: Data Primer yang diolah, 2018

\section{Uji Normalitas}

Uji normalitas merupakan salah satu bagian dari uji persyaratan analisis data atau uji asumsi klasik, artinya sebelum melakukan analisis yang sesungguhnya data tersebut harus diuji kenormalan distribusinya. Uji normalitas data dalam penelitian ini menggunakan uji Kolmogorov Smirnov terhadap data residual regresi dan dilakukan dengan program SPSS V 23.

Kriteria yang digunakan dalam uji normalitas ialah apabila hasil perhitungan Uji One Sample Kolmogorov-Smirnov dengan menggunakan taraf signifikan 0.05. data dinyatakan berdistribusi normal jika signifikan lebih besar dari 5\%. Hasul pengujian normalitas dengan Kolmogorov-Smirnov dapat dilihat secara ringkas dalam tabel berikut:

Tabel IV.6

Uji Normalitas Kolmogrov-Smirnov One-Sample Kolmogorov-Smirnov Test

\begin{tabular}{|ll|r|}
\hline & & \multicolumn{2}{|c|}{$\begin{array}{c}\text { Unstandardized } \\
\text { Residual }\end{array}$} \\
\hline $\mathrm{N}$ & & 51 \\
Normal Parameters & a,b & Mean \\
& Std. Deviation &, ooooooo \\
Most Extreme & Absolute & 2,50748479 \\
Differences & Positive &, 079 \\
& Negative &, 059 \\
Test Statistic & &,- 079 \\
Asymp. Sig. (2-tailed) & &, 079 \\
\hline
\end{tabular}

a. Test distribution is Normal.

b. Calculated from data.

c. Lilliefors Significance Correction.

$\mathrm{d}$. This is a lower bound of the true significance.

Sumber: Data Primer yang diolah pada SPSS versi 23, 2018.

Uji normalitas yang digunakan untuk melihat apakah data yang dipakai berdistribusi normal atau tidak. Dari data diatas, terlihat bahwa pada semua variabel memiliki nilai signifikansi (Asymp. Sig 2-tailed) $\geq 0$ 0,05 yaitu 0,200, 
Maka dapat disimpulkan bahwa semua variabel pada penelitian ini berdistribusi normal. Dengan demikian telah memenuhi syarat statistik parametrik.

\section{Uji linearitas}

Uji linearitas bertujuan untuk mengetahui apakah dua variabel mempunyai hubungan yang linear atau tidak secara signifikan Uji ini digunakan sebagai persyaratan dalam analisis korelasi pearson atau regresi linear. Pengujian pada SSPS dengan menggunakan test for linearity pada taraf signifikan 0,05. Dua variabel dikatakan mempunyai hubungan yang linear bila signifikan kurang dari 0,05 .

1. Uji Linearitas Pelatihan $\left(\mathrm{X}_{1}\right)$

Uji linearitas digunakan untuk mengetahui apakah variabel pelatihan dan kinerja pegawai mempunyai hubungan yang linear atau tidak secara signifikan.

Tabel IV. 7

Hasil Output Uji Linearitas Pelatihan

ANOVA Table

\begin{tabular}{|c|c|c|c|c|c|c|c|}
\hline & & & $\begin{array}{c}\text { Sum of } \\
\text { Square } \\
\text { s }\end{array}$ & $\mathrm{df}$ & $\begin{array}{c}\text { Mean } \\
\text { Squar } \\
\text { e }\end{array}$ & $\mathrm{F}$ & Sig. \\
\hline \multirow{5}{*}{$\begin{array}{l}\text { Kinerja_Pe } \\
\text { gawai * } \\
\text { Pelatihan }\end{array}$} & Bet & (Combine & 279,147 & 19 & 14,692 & 2,091 & ,033 \\
\hline & $\begin{array}{l}\mathrm{n} \\
\text { Gro }\end{array}$ & Linearity & 173,159 & 1 & & $\begin{array}{r}24,64 \\
2\end{array}$ & ,o00 \\
\hline & ups & $\begin{array}{l}\text { Deviation } \\
\text { from } \\
\text { Linearity }\end{array}$ & $\begin{array}{r}105,98 \\
8\end{array}$ & 18 & 5,888 & ,838 & 647 \\
\hline & \multicolumn{2}{|c|}{ Within Groups } & 217,833 & 31 & 7,027 & & \\
\hline & \multicolumn{2}{|c|}{ Total } & $\begin{array}{r}496,98 \\
0\end{array}$ & $\begin{array}{l}5 \\
0\end{array}$ & & & \\
\hline
\end{tabular}

Sumber: Data Primer yang diolah pada SPSS versi 23, 2018.

Hasil uji linearitas dapat dilihat pada output ANOVA Table. ${ }^{15}$ Dapat diketahui bahwa nilai signifikansi pada Linearity sebesar o,ooo. Karena nilai signifikansi lebih kecil dari 0,05 maka dapat disimpulkan bahwa antara variabel pelatihan dan kinerja pegawai terdapat hubungan yang linear.

\section{Uji Linearitas Motivasi $\left(X_{2}\right)$}

${ }^{15}$ Duwi Priyatno, SPSS 22: Pengolah Data Terpraktis, (Yogyakarta:Andi Offset, 2014), hlm. 84. 
Tabel IV. 8

Hasil Output Uji Linearitas Motivasi

ANOVA Table

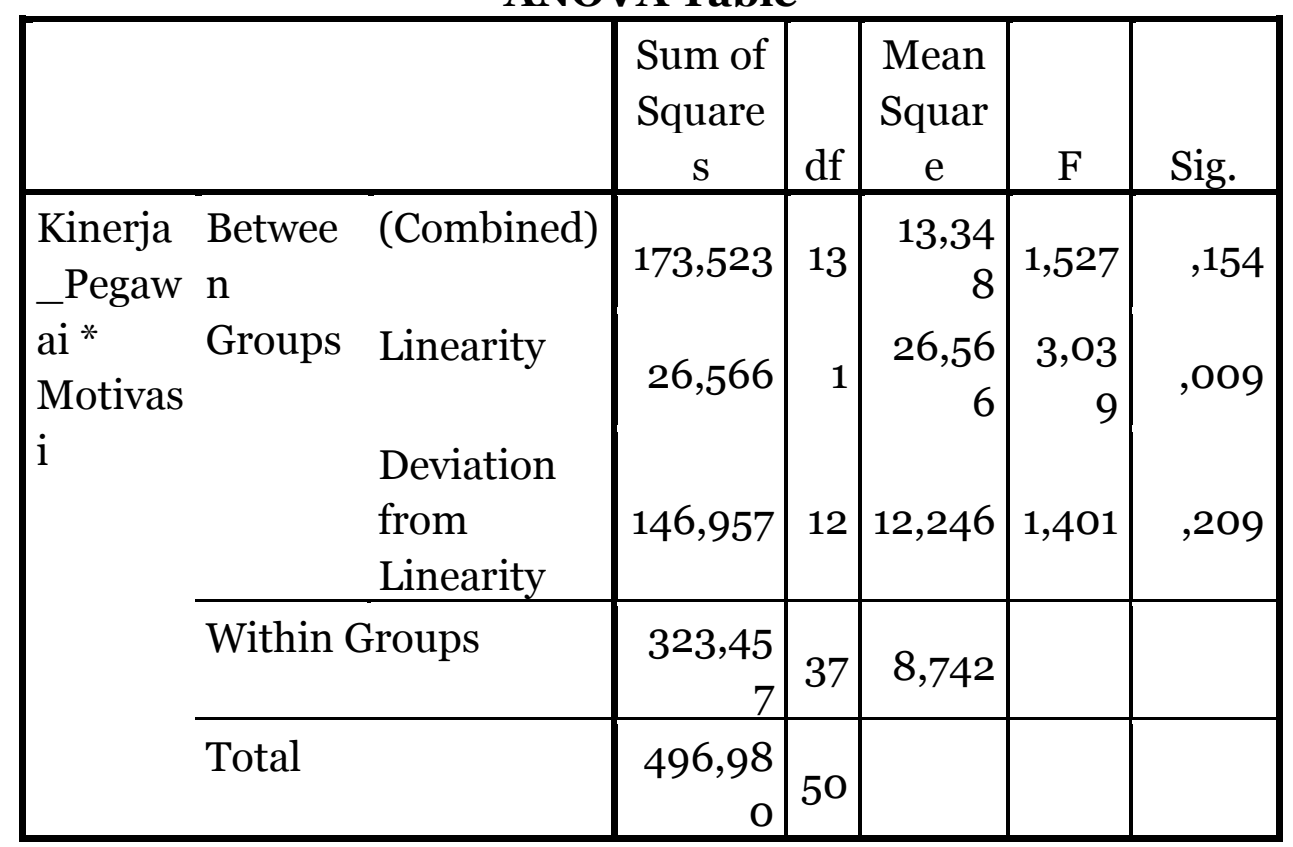

Sumber: Data Primer yang diolah pada SPSS versi 23, 2018.

Hasil uji linearitas dapat dilihat pada output ANOVA Table. ${ }^{16}$ Dapat diketahui bahwa nilai signifikansi pada Linearity sebesar 0,009. Karena nilai signifikansi lebih kecil dari 0,05 maka dapat disimpulkan bahwa antara variabel motivasi dan kinerja pegawai terdapat hubungan yang linear.

\section{Uji asumsi klasik}

\section{a. Uji Multikolinearitas}

Multikolineritas artinya antar variabel independen yang terdapat dalm model regresi memiliki hubungan linear yang sempurna atau mendekati sempurna. Model regresi yang baik seharusnya tidak terjadi korelasi sempurna atau mendekati sempurna diantara variabel bebasnya. ${ }^{17}$ Untuk mendeteksi adanya multikolinearitas dapat dilihat dari nilai tolerance dan VIF (Variance Inflaction Factor). Suatu regresi dikatakan terdeteksi multikolinearitas, jika nilai VIF kurang dari 10 dan tolerance lebih dari o,1 maka dinyatakan tidak terjadi multikolinearitas. ${ }^{18}$ Berikut hasil uji multikolinearitas:

\footnotetext{
${ }^{16}$ Ibid.

${ }^{17}$ Duwi Priyatno, Op.Cit., hlm.99.

${ }^{18}$ Ibid., hlm.103.
} 
Tabel IV. 9

Hasil Output Uji Multikolinearitas

Coefficients ${ }^{\mathrm{a}}$

\begin{tabular}{|ll|r|r|}
\hline \multirow{2}{*}{ Model } & \multicolumn{2}{|c|}{ Collinearity Statistics } \\
\cline { 2 - 4 } & (Constant) & Tolerance & \multicolumn{2}{|c|}{ VIF } \\
\hline 1 & Pelatihan &, 974 & 1,027 \\
& Motivasi &, 974 & 1,027 \\
\hline
\end{tabular}

Sumber: Data Primer yang diolah pada SPSS versi 23, 2018.

Berdasarkan tabel diatas dapat di ketahui nilai VIF untuk variabel pelatihan adalah 1,027<10, variabel Motivasi 1.027<10, dengan demikian dapat disimpulkan nilai VIF dari kedua variabel diatas lebih kecil dari 10 $(\mathrm{VIF}<10)$.

Sementara itu nilai Tolerance untuk variabel pelatihan adalah 0,974 > 0,1, motivasi 0,974> 0,1 Jadi dapat disimpulkan nilai tolerance dari kedua variabel adalah lebih besar dari 0,1 (Tolerance > 0,1). Berdasarkan penilaian diatas dapat disimpulkan bahwa tidak terjadi multikolinearitas.

\section{b. Uji Heteroskedatisitas}

Uji heteroskedastisitas digunakan untuk mengetahui ada atau tidaknya penyimpanagan heteroskedostisidas. Jika nilai signifikan<0,05 maka akan terjadi heterokedastitas, sebaliknya jika nilai signifikan>0,05 maka tidak terjadi heterokedastisitas. Uji heteroskedastisitas dalam penelitian ini menggunakan uji Spearman rho. Berikut hasil uji heteroskedatisitas:

Tabel IV. 10

Hasil Output Uji Heterokedastisitas

Correlations

\begin{tabular}{|ll|r|r|r|}
\hline & & $\begin{array}{c}\text { Pelatiha } \\
\mathrm{n}\end{array}$ & $\begin{array}{c}\text { Motivas } \\
\mathrm{i}\end{array}$ & $\begin{array}{c}\text { Unstandar } \\
\text { dized } \\
\text { Residual }\end{array}$ \\
\hline $\begin{array}{l}\text { Spearma } \\
\text { n's rho }\end{array}$ & Pelatihan Correlatio \\
$\mathrm{n}$ & 1,000 &, 130 &, 000 \\
& $\begin{array}{l}\text { Coefficien } \\
\mathrm{t}\end{array}$ & &, 363 &, 997 \\
& $\begin{array}{l}\text { Sig. (2- } \\
\text { tailed) } \\
\mathrm{N}\end{array}$ & 51 & 51 & 51 \\
\hline
\end{tabular}




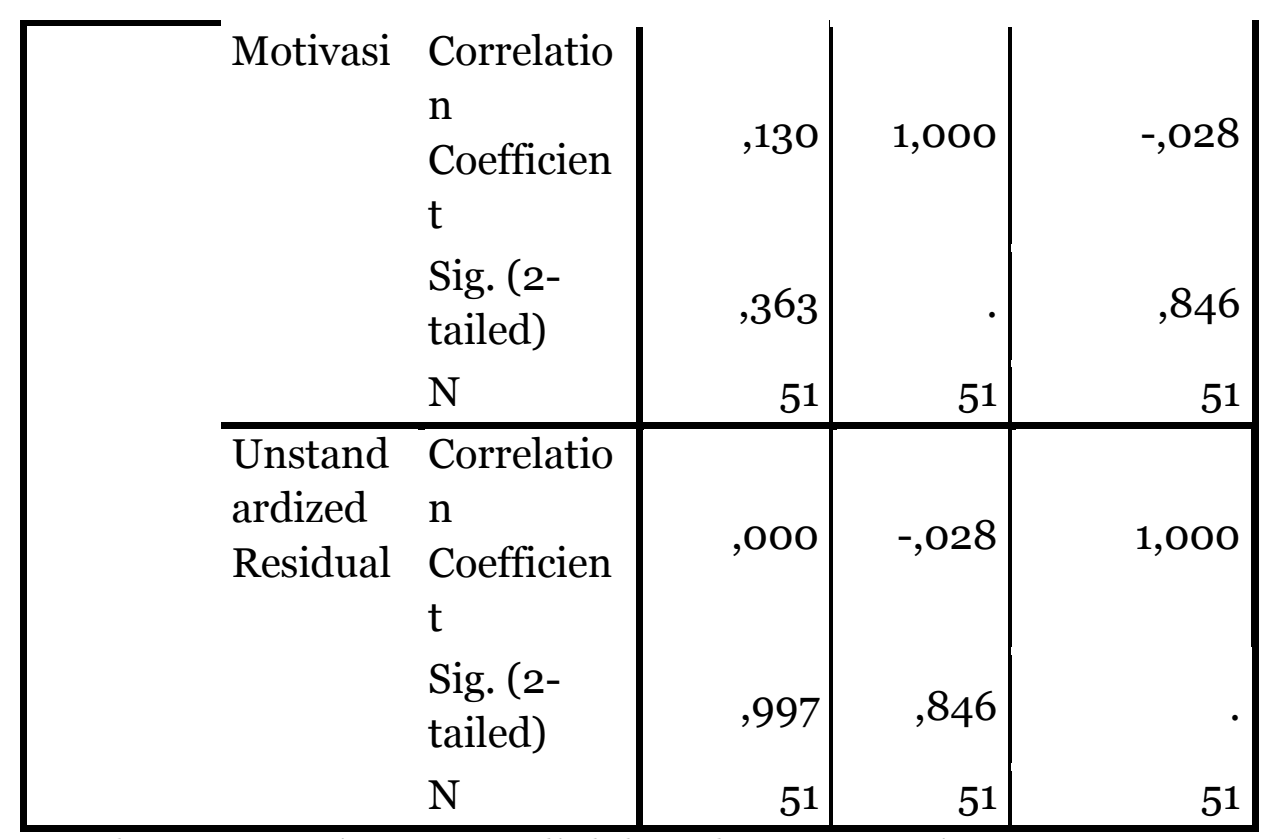

Sumber: Data Primer yang diolah pada SPSS versi 23, 2018.

Pada tabel diatas uji heterokedastisitas dilakukan dengan metode korelasi spearman's rho, menunjukkan bahwa nilai korelasi antara variabel pelatihan dan motivasin dengan Unstandardized Residual memiliki signifikansi (Sig 2 tailed) lebih dari o,05 yaitu masing-masing 0,997 dan 0,846. Karena signifikansi lebih besar dari 0,05 dapat disimpulkan bahwa tidak terjadi masalah heterokedastisitas.

\section{Analisis regresi berganda}

Tabel IV.11

Hasil Output Uji Analisis Regresi Linear Berganda

Coefficients ${ }^{\mathbf{a}}$

\begin{tabular}{|c|c|c|c|c|c|}
\hline \multirow[b]{2}{*}{ Model } & \multicolumn{2}{|c|}{$\begin{array}{c}\text { Unstandardized } \\
\text { Coefficients }\end{array}$} & \multirow{2}{*}{$\begin{array}{c}\text { Standardize } \\
\mathrm{d} \\
\text { Coefficients } \\
\text { Beta }\end{array}$} & \multirow[b]{2}{*}{$\mathrm{t}$} & \multirow[b]{2}{*}{ Sig. } \\
\hline & $\mathrm{B}$ & Std. Error & & & \\
\hline $\begin{array}{ll}1 & \text { (Constan } \\
\text { t) }\end{array}$ & 21,718 & 4,399 & & 4,937 & , OOO \\
\hline Pelatihan & ,339 & , O70 &, 568 & 4,881 & , OOO \\
\hline Motivasi & ,111 & ,093 & ,140 & 1,701 &, 236 \\
\hline
\end{tabular}

a. Dependent Variable: Kinerja_Pegawai

Sumber: Data Primer yang diolah pada SPSS versi 23, 2018.

Analisis regresi digunakan untuk mengetahui pengaruh pelatihan dan motivasi terhadap kinerja pegawai.

Persamaan regresinya sebagai berikut:

$\mathrm{Y}=\mathrm{a}+\mathrm{b}_{1} \mathrm{X}_{1}+\mathrm{b}_{2} \mathrm{X}_{2+} \mathrm{e}$ 
$\mathrm{KK}=21,718+(0,339)$ Pelatihan $+(0,111)$ Motivasi $+\mathrm{e}$

Dari persamaan regresi itu dapat diartikan bahwa:

a. Nilai konstanta sebesar 21,718 dengan parameter positif menunjukkan bahwa apabila pelatihan dan motivasi, dianggap konstan atau ditiadakan, maka kinerja pegawaiPuskesmas Kecamatan Muara Batang Toru sebesar 21,718 satuan.

b. Nilai koefisien pelatihan sebesar 0,339 menunjukkan bahwa apabila pelatihan meningkat sebesar 1 satuan, maka akan meningkatkan kinerja pegawai sebesar 0,339 satuan, dan sebaliknya dengan anggapan variabel lain tetap. Koefisien bernilai positif artinya terjadi hubungan positif antara pelatihan dengan kinerja pegawai.

c. Nilai Koefisien religiusitas sebesar o,111 menunjukkan bahwa apabila motivasi meningkat sebesar 1 satuan, maka akan meningkatkan kinerja pegawai sebesar 0,111 satuan, dan sebaliknya dengan anggapan variabel lain tetap. Koefisien bernilai positif artinya terjadi hubungan positif antara motivasi dengan kinerja pegawai.

\section{Uji koefisien determinasi $\left(R^{2}\right)$}

Koefisien determinasi $\left(\mathrm{r}^{2}\right)$ mengukur tingkat ketepatan atau kecocokan (goodness of fit) dari regresi linear berganda, yaitu merupakan persentase sumbangan X terhadap Variasi naik turunnya Y. Adapun hasil dari koefisien determinasi $\left(\mathrm{R}^{2}\right)$ sebagai berikut:

\section{Tabel IV.12}

Uji Koefisien Determinasi $\left(R^{2}\right)$

Model Summaryb

\begin{tabular}{|l|l|r|c|c|}
\hline $\begin{array}{l}\text { Mode } \\
1\end{array}$ & $\mathrm{R}$ & $\begin{array}{c}\mathrm{R} \\
\text { Square }\end{array}$ & $\begin{array}{c}\text { Adjusted R } \\
\text { Square }\end{array}$ & \multicolumn{2}{|c|}{$\begin{array}{c}\text { Std. Error of the } \\
\text { Estimate }\end{array}$} \\
\hline 1 &, $606^{\mathrm{a}}$ &, 367 &, 341 & \\
\hline
\end{tabular}

a. Predictors: (Constant), Motivasi, Pelatihan

b. Dependent Variable: Kinerja_Pegawai

Sumber: Data Primer yang diolah pada SPSS versi 23, 2018.

Berdasarkan tabel IV.12 diperoleh angka R sebesar 0,606 artinya korelasi antara variabel pelatihan dan motivasi terhadap kinerja pegawai sebesar o,606.Hubungan antara pelatihan dan motivasi terhadap kinerja pegawai berada pada interpretasi hubungan kuat. Nilai R Square sebesar 0,367 artinya pelatihan dan motivasi mampu menjelaskan variabel dependen atau kinerja pegawai sebesar 36,7 persen sedangkan 63,3 persen dijelaskan oleh variabel lain yang tidak menjadi fokus penelitian seperti menurut Steers faktor-faktor yang mempengaruhi kinerja yakni kemampuan, keperibadian dan minat kerja.

\section{Uji hipotesis}

\section{a. Uji t}


Uji t digunakan untuk mengetahui pengaruh variabel independen terhadap variabel dependen. Uji $t$ bertujuan untuk mengetahui pengaruh variabel pelatihan dan motivasi terhadap kinerja pegawai. Adapun hasil output dari regresi sebagai berikut:

\begin{tabular}{|c|c|c|c|c|c|}
\hline & & $\begin{array}{l}\text { Tabel. IV. } \\
\text { sil Output } \\
\text { oefficients }\end{array}$ & $\begin{array}{l}13 \\
\text { Uji t }\end{array}$ & & \\
\hline \multirow[b]{2}{*}{ Model } & \multicolumn{2}{|c|}{$\begin{array}{c}\text { Unstandardized } \\
\text { Coefficients }\end{array}$} & \multirow{2}{*}{$\begin{array}{c}\text { Standardize } \\
\mathrm{d} \\
\text { Coefficients }\end{array}$} & \multirow[b]{2}{*}{$\mathrm{t}$} & \multirow[b]{2}{*}{ Sig. } \\
\hline & $\mathrm{B}$ & Std. Error & & & \\
\hline $\begin{array}{ll}1 & \text { (Constan } \\
\text { t) }\end{array}$ & 21,718 & 4,399 & & 4,937 & , OOO \\
\hline Pelatihan & ,339 & , 070 &, 568 & 4,881 & , OOO \\
\hline Motivasi &, 111 & ,093 & ,140 & 1,701 & ,236 \\
\hline
\end{tabular}

a. Dependent Variable: Kinerja_Pegawai

Sumber: Data Primer yang diolah pada SPSS versi 23, 2018.

Dari hasil output tabel IV.13 dapat dilihat bahwa thitung untuk variabel pelatihan $\left(\mathrm{X}_{1}\right)$ sebesar 4,881 sedangkan tabel diperoleh 1,676 ini berarti thitung $>$ ttabel $(4,881<1,676)$ berarti $h_{01}$ ditolak dan $h_{a 1}$ diterima. Jadi dapat disimpulkan bahwa dari hasil uji t pelatihan berpengaruh secara parsial terhadap kinerja pegawai.

Sedangkan thitung untuk variabel motivasi $\left(\mathrm{X}_{2}\right)$ sebesar 1,701 tabel diperoleh 1,676 ini berarti thitung $>$ tabel $(1,701>1,676)$, maka $h_{02}$ ditolak dan $h_{a 2}$ diterima. Jadi dapat disimpulkan bahwa dari hasil uji t motivasi berpengaruh secara parsial terhadap kinerja pegawai.

\section{b. Uji F}

Uji $\mathrm{F}$ digunakan untuk mengetahui pengaruh variabel independen terhadap variabel dependen secara simultan.Uji $F$ bertujuan untuk mengetahui pengaruh pelatihan dan motivasi terhadap kinerja pegawai. Adapun hasil output dari regresi sebagai berikut:

Tabel IV. 14

Hasil Output Uji F

ANOVAa

\begin{tabular}{|c|c|c|c|c|c|c|}
\hline \multicolumn{2}{|c|}{ Model } & $\begin{array}{l}\text { Sum of } \\
\text { Squares }\end{array}$ & $\mathrm{df}$ & $\begin{array}{c}\text { Mean } \\
\text { Square }\end{array}$ & $\mathrm{F}$ & Sig. \\
\hline \multirow[t]{3}{*}{1} & $\begin{array}{l}\text { Regressio } \\
\mathrm{n}\end{array}$ & 182,606 & 2 & 91,303 & 13,941 & ,OOO \\
\hline & Residual & 314,374 & 48 & 6,549 & & \\
\hline & Total & 496,980 & 50 & & & \\
\hline
\end{tabular}


a. Dependent Variable: Kinerja_Pegawai

b. Predictors: (Constant), Motivasi, Pelatihan

Sumber: Data Primer yang diolah pada SPSS versi 23, 2018.

Berdasarkan tabel IV.14 dijelaskan bahwa $F_{\text {hitung }}>F_{\text {tabel }}(13,941>3,19)$, maka $h_{03}$ ditolak dan $h_{a 3}$ diterima. Jadi dapat disimpulkan bahwa pelatihan dan motivasi berpengaruh secara simultan terhadap kinerja pegawai.

\section{DAFTAR PUSTAKA}

Amini, Perilaku Organisasi, Bandung: Citapustaka Media, 2004.

Anwar

Prabu

Mangkunegara,

PerencanaandanPengembanganSumberDayaManusia, Bandung: PT.

Refika Aditama, 2003.

Arsi Laksmi Riani, BudayaOrganisasi, Yogyakarta: Graha Ilmu, 2011.

Azuar Zuliandi, Irfan,dkk. Metode Penelitian Bisnis Konsep \& Aplikasi, Medan:

Umsu Press, 2015.

Basir Bartos, Manajemen Sumber Daya Manusia. Suatu Pendekatan Makro,

Jakarta: Bumi Aksara, 1990.

Departemen Agama RI, Al-Qur'andanTerjemahan , Bandung: PT. Sygma Examedia Arkanleema, 2007.

Dessler Gery, Managemen Sumber Daya Manusia, Indonesia: PT Intan Sejati Klaten 2006.

Duwi Priyatno, SPSS 22, Pengolahan Data Terpraktis, Yogyakarta: CV. Andi Offset, 2014.

Dwi Priyatno, Mandiri Belajar SPSS, Yogyakarta: Media Kom, 2008.

Dwi Suwiknyo, Kompilasi Tafsir Ayat-ayat Ekonomi Islam, Yogyakarta: Pustaka Pelajar, 2010

Edy Sutrisno, BudayaOrganisasi, Jakarta: Kencana Prenadamedia Group, 2010. Hasibuan, Abdul Nasser, Effects of Auditor Quality on Market-besed and Accounting-based Financial Statement Quality and Its Impacts on Economic Consequences (A Case Indonesian Capital Market), Internasional Journal of Economic Research No.14 (2017).

Muda, Iskandar dan Abdul Nasser Hasibuan, Public Discovery of The Concept of Money with Value of Time Emerald Reach Proceeding Series (Proceeding of MICoMS 2017), Vol 1 pp.255-261 
PENGARUH... Nofinawati 